\title{
Effects of forest management practices on red-shouldered hawks in Ontario
}

\author{
by Brian J. Naylor ${ }^{1}$, James A. Baker ${ }^{2}$, and Kandyd J. Szuba ${ }^{3}$
}

\begin{abstract}
The red-shouldered hawk (Buteo lineatus) is a species of special concern throughout its northern range. It is considered to be sensitive to forest management practices because it requires dense mature hardwood forest for nesting. In Ontario, guidelines that prescribe spatial and temporal buffers were developed in about 1990 to mitigate the potential impacts of harvesting. We monitored 84 nesting areas of red-shouldered hawks in central and southeastern Ontario from 1988 to 1995 to describe the effects of forest management practices on the occupancy and productivity of nesting areas, to evaluate the effectiveness of the guidelines, and recommend modifications as appropriate. The number of years nesting areas had been used previously had a significant negative effect on activity status, but not on nest success. Nesting areas harvested with application of the guidelines had a similar probability of being active to those in uncut forest but nesting areas harvested without application of the guidelines did not. Neither the area nor proximity of selection cuts with a moderate to high residual basal area $\left(\geq 18 \mathrm{~m}^{2} / \mathrm{ha}\right)$ affected the activity status of nesting areas. In contrast, the area and proximity of heavy cuts (shelterwood cuts or selection cuts with a residual basal area of $14-16 \mathrm{~m}^{2} / \mathrm{ha}$ ) appeared to have a negative effect on activity status. When nesting areas were active, the proximity and amount of harvesting did not influence nest success. We concluded that the impact of harvesting on the activity status of nesting areas could be mitigated by prohibiting heavy cuts within $300 \mathrm{~m}$ of active nests and retaining $\geq 20$ ha of forest dominated by tolerant and mid-tolerant hardwood trees, $\geq 18 \mathrm{~m}$ tall, with $\geq 70 \%$ canopy closure around nests.
\end{abstract}

Key words: Buteo lineatus, effectiveness monitoring, habitat guidelines, nest success, Ontario, red-shouldered hawk, forest management, selection, shelterwood, tolerant hardwoods

La buse à épaulettes (Buteo lineatus) est une espèce d'intérêt spécial partout dans son habitat nordique. Elle est considérée comme étant sensible relativement aux pratiques d'aménagement forestier car elle a besoin de forêts denses de feuillus à maturité pour nidifier. En Ontario, les directives qui prescrivent les zones tampons sur le terrain et dans le temps ont été élaborées approximativement en 1990 afin de mitiger les impacts potentiels de l'exploitation. Nous avons observé 84 zones de nidification de la buse à épaulettes dans le centre et sud-est de l'Ontario de 1988 à 1995 afin de décrire les effets des pratiques d'aménagement forestier sur la présence et la productivité des zones de nidification, afin d'évaluer l'efficacité des directives et afin de recommander des modifications si nécessaire. Le nombre d'année-zone de nidification utilisé précédemment a eu un effet négatif et significatif sur l'état d'activité, mais non sur la réussite de la nidification. Les zones de nidifications récoltées selon les directives ont atteint une probabilité similaire aux nids actifs dans la forêt non récoltée mais les zones de nidifications récoltées sans tenir compte des directives ne l'ont pas atteint. Ni la superficie, ni la proximité des coupes de jardinage avec une surface terrière résiduelle moyenne à élevée (= $\left.18 \mathrm{~m}^{2} / \mathrm{ha}\right)$ ont affecté l'état d'activité des zones de nidification. Par contre, la superficie et la proximité de coupes importantes (coupes progressives ou coupes de jardinage ayant une surface terrière résiduelle de $14-16 \mathrm{~m}^{2} / \mathrm{ha}$ ) semblent avoir un effet négatif sur l'état d'activité. Lorsque les nids sont occupés, la proximité et l'importance de la récolte n'ont pas eu d'influence sur le taux de nidification. Nous avons conclu que l'effet de la récolte sur l'état d'activité des zones de nidifications pourrait être mitigé en interdisant des coupes importantes à moins de 300 $\mathrm{m}$ des nids occupés et en conservant 20 ha de forêt dominée par des feuillus tolérants à moyennement tolérants de $18 \mathrm{~m}$ de hauteur, ainsi qu'un couvert forestier de $70 \%$ autour des nids.

Mots-clés: Buteo lineatus, suivi de l'efficacité, directives sur l'habitat, succès de la nidification, Ontario, buse à épaulettes, aménagement forestier, jardinage, coupe progressive, feuillus tolérants

\section{Introduction}

The red-shouldered hawk (Buteo lineatus) is classified as rare, vulnerable, threatened, endangered or a species of special concern throughout most of the northern part of its distribution (Crocoll 1994). Prior to its decline during the mid 1900s, it was one of the most common diurnal raptors throughout much of its range (Crocoll 1994).

The red-shouldered hawk generally nests in mature hardwood forest and hunts in both mature forest and riparian habitats adja-

\footnotetext{
${ }^{1}$ Ontario Ministry of Natural Resources, Southern Science and Information Section, 3301 Trout Lake Road, North Bay, ON P1A 4L7 E-mail: brian.naylor@mnr.gov.on.ca

${ }^{2}$ Ontario Ministry of Natural Resources, Ontario Forest Research Institute, 1235 Queen Street, Sault Ste. Marie, ON P6A 2E5.

${ }^{3}$ Domtar Inc., Forest Products Group, 79 Tudhope Street, Espanola, ON P5E 1S6.
}

cent to ponds, wetlands, and lakes (Armstrong and Euler 1982, Morris and Lemon 1983, Preston et al. 1989, Howell and Chapman 1997, McLeod et al. 2000). Much of the decline in numbers observed in the 1900s has been attributed to removal or fragmentation of mature hardwood forest (Crocoll 1994). The effects of habitat loss and fragmentation may have been exacerbated further by forest harvesting (even partial harvesting) around nests (Bryant 1986).

In the late 1980s, the Ontario Ministry of Natural Resources (OMNR) became concerned about the potential impact of forest management practices on nesting red-shouldered hawks. Extensive surveys were conducted to locate active nests and guidelines were developed to direct forest management practices in the vicinity of nests to minimize impacts. These guidelines prescribe spatial and temporal buffers and were similar in design to those developed for a variety of raptor species across 
North America over the past two decades (see Richardson and Miller 1997).

The guidelines require the establishment of a 28-ha areaof-concern (AOC) to protect nesting areas that have been active at least once within the previous five years. Within the AOC, no harvesting is permitted at any time within 150 $m$ of the most recently active (primary) nest (a circular 7ha reserve). Partial harvesting

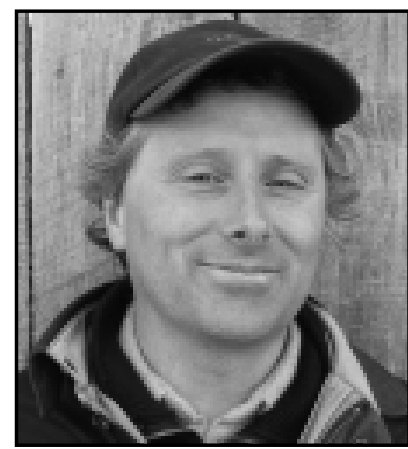

Brian J. Naylor

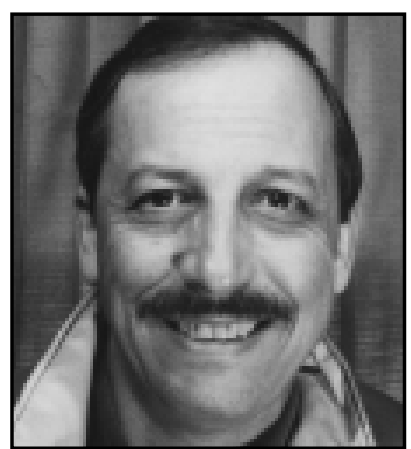

James A. Baker

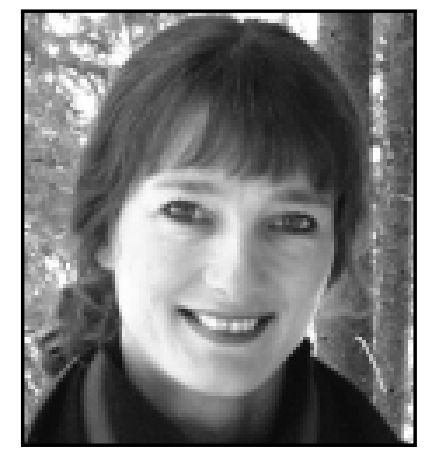

Kandyd J. Szuba may occur within the remaining 21 ha of the AOC (the modified area), but it may not occur during the breeding season (March 1 to July 31) and canopy closure may not be reduced below $70 \%$. Old nests that are not currently being used (satellite nests) receive a 20-m reserve. The two zones of the AOC can be laid out as concentric circles (in which case the AOC would have a 300$\mathrm{m}$ radius). However, the guidelines recommend that the modified area be established as a polygon that encompasses most of the satellite nests, protects the best available nesting habitat, and connects nesting and feeding habitats (Szuba and Naylor 1998).

The guidelines were based largely on expert opinion because few studies reported on the effects of forest management practices on red-shouldered hawks around 1990. The objectives of this study were to describe the effects of forest management practices on the occupancy and productivity of nests, evaluate the effectiveness of the guidelines in mitigating these effects, and recommend modifications as appropriate.

\section{Study Area}

Red-shouldered hawk nests were monitored throughout central and southeastern Ontario (Fig. 1) from 1988 to 1995. Most nests were found within the Algonquin-Pontiac, Middle Ottawa, and Georgian Bay sections of the Great Lakes - St. Lawrence Forest Region (Rowe 1972). The landscape of the study region was generally bedrock-controlled, with elevation ranging from 150 to $500+\mathrm{mASL}$. The most common landforms originated from glacial activities and soils were highly variable, ranging from sandy to loamy and shallow to deep (Chambers et al. 1997).

The study region's forest cover was characterized by a mixture of hardwood- and conifer-dominated communities (Chambers et al. 1997). About half the forest was dominated by shade-tolerant and mid-tolerant hardwood communities that represented potential nesting habitat for red-shouldered hawks. Sugar maple (Acer saccharum) dominated most of these communities. Common associates were yellow birch (Betula alleghaniensis), hemlock (Tsuga canadensis), American beech (Fagus grandifolia), red oak (Quercus rubra), basswood (Tilia americana), black cherry (Prunus serotina), white ash (Fraxinus americana), white birch (B. papyrifera), and ironwood (Ostrya virginiana). Tolerant and mid-tolerant hardwood forest in the vicinity of redshouldered hawk nests was managed using primarily the single-tree selection system, and to a lesser degree, the uniform shelterwood system. Variation in silvicultural system used and intensity of harvest was influenced by stand composition, structure, and quality (OMNR 1998).

\section{Methods \\ Monitoring nesting areas}

Eighty-four active red-shouldered hawk nesting areas were located by OMNR staff, consultants, and naturalists from 1988 to 1992 using methods described by Naylor and Szuba (1998). We defined a nesting area as a block of suitable habitat encompassing an active (primary) nest and associated satellite nests. Individual nesting areas were monitored up to six years (median three years) for a total of 280 nest-years (i.e., a nest-year represents one nesting area monitored for one year).

We assessed two measures of performance at each nesting area: 1) activity status and 2) nest success (Table 1). Each year, nesting areas were searched once (or twice if status could not be confirmed during the first visit) during April and early May to determine activity status. Trained observers visited each known nest within a nesting area and recorded any evidence of nesting activity (see below). If known nests showed no signs of activity, observers searched for new nests within a few hundred metres, repeatedly broadcasting a recorded call of the redshouldered hawk. A nest (and thus nesting area) was considered to be active if an incubating bird was present or if it was thickly decorated with conifer foliage or covered with down feathers and one or more red-shouldered hawks was observed nearby (Naylor and Szuba 1998). New active nests located $>$ $500 \mathrm{~m}$ from previously used nests were considered to represent new nesting areas.

Active nests were checked from late June to early July to determine success. Observers examined nests from vantage points that afforded the best view of the nest and its contents. We considered nests successful if there was evidence that well-developed chicks were present (i.e., at least one chick in or near the nest, parents delivering food to the nest, many down feathers on the rim, or a large amount of whitewash on the nest or around the nest tree (Naylor and Szuba 1998)).

During all visits, observers spent as little time as possible at nests, avoided flushing incubating or brooding adults, and placed minimal marking around nests to minimize the influence of observers on use and success of nests.

\section{Forest management practices within nesting areas}

Some amount of harvesting (primarily single-tree selection cuts but some uniform shelterwood seeding cuts) was conducted within $500 \mathrm{~m}$ of the primary nest at 33 of the 84 nesting areas. We did not consider harvesting beyond $500 \mathrm{~m}$ because other work suggested little impact on habitat suitability (Naylor et al. 


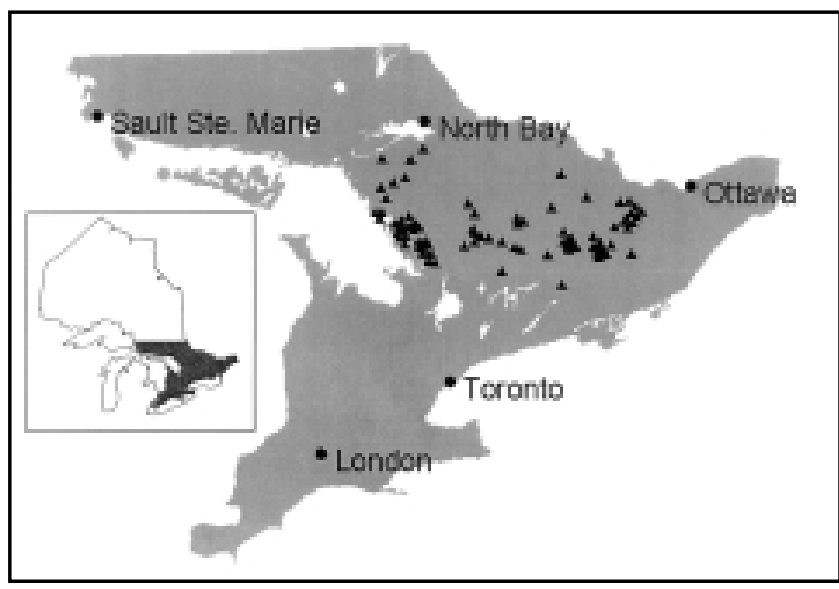

Fig. 1. Location of 84 red-shouldered hawk nests (triangles) monitored in central and southeastern Ontario from 1988 to 1995.

1994). Following harvest, nesting areas were monitored up to five years (median three years) for a total of 90 nest-years. Because harvesting in hardwood stands is generally prohibited during late spring and early summer to avoid logging damage to residual trees (OMNR 1998), all but two of the harvest operations within nesting areas occurred outside the nesting season. Consequently, our results represented only the short-term impact of harvesting conducted outside the nesting season.

At 14 sites, harvesting was modified following the guidelines. At the other 19 sites, either normal harvesting occurred (with only a 20-m reserve around each nest) or harvesting was modified but not to the extent prescribed by the guidelines. These sites did not receive the full protection of the guidelines because either 1) the area was cut before the active nest was discovered or, 2) the area was cut before the guidelines were implemented so a less restrictive prescription was applied. Only one harvested area received additional silvicultural treatment (i.e., site preparation, planting, or tending).

Using OMNR maps (scale 1:15 840), we measured, within $500 \mathrm{~m}$ of each primary nest, the total area cut, the area by type of cut, the area that remained uncut, the distance to cuts (by type), and noted the number of nesting seasons since cutting had occurred (see Table 1 for definitions of the variables assessed).

\section{Statistical analysis}

We compared activity status and nest success between cut and uncut nesting areas using tests of independence (SPSS Inc. 1997). We also used logistic regression (LR) analysis (SPSS Inc. 1997) to model relationships between activity status, nest success, and a suite of variables related to calendar year, number of years nesting areas were used, number of years since harvest, and various measured aspects of harvesting (Table 1). Calendar years and cut status were incorporated into LR models as dummy variables. Data were LN-transformed to improve model fit or meet statistical assumptions. Stepwise models used forward selection with the likelihood-ratio criterion $(P=0.10$ for entry, $P=0.15$ for removal). Goodness-of-fit was judged by Nagelkerke's $R^{2}$, the classification rate, and Hosmer and Lemeshow's goodness-of-fit test. Data collected from multiple years at individual nests were not independent. However, such lack of independence should not have resulted in biased estimates of model parameters but may have affected estimates of variance and thus tests of significance (i.e., underestimated $P$-values) (see West 1995). Consequently, reported $P$-values should be viewed cautiously.

Sample size varied among analyses. Models predicting activity status of nesting areas were based on 280 nest-years. Models predicting nest success used data from active nesting areas only (147 nest-years); success was not determined for all active nests. Power of some tests $(\alpha=0.05, \beta=0.20)$ was estimated using PASS2000 (NCSS 2000).

\section{Results \\ Influence of calendar year and number of years nesting areas used}

Logistic regression models containing at least one calendar year variable were significant predictors of the activity status of nesting areas $\left(X^{2}=29.458, P<0.001\right)$ and marginally significant predictors of nest success $\left(X^{2}=5.780, P=0.056\right)$. However, the models explained a small proportion of the variability in both activity status $\left(R^{2}=0.142\right)$ and nest success $\left(R^{2}=0.052\right)$. Number of years a nesting area had been used previously (YrsUsed) was a better predictor of the activity status of nesting areas $\left(X^{2}=71.816, P<0.001, R^{2}=0.321\right)$, but not nest success $(P=0.774)$.

\section{Effects of forest management practices}

Activity Status of Nesting Areas: Nesting areas that had experienced harvesting appeared to have a lower rate of activity (active in $57.8 \%$ of 90 nest-years) than those that did not (active in $75.8 \%$ of 190 nest-years) $(G=9.176, P=0.002)$. However, this relationship was confounded by YrsUsed. When YrsUsed was controlled (LR), cut and uncut nesting areas did not differ in the frequency of activity $(P=0.363)$. Our sample size permitted us to detect a difference in rate of activity between cut and uncut nesting areas as small as $18 \%$.

Nesting areas that had experienced harvesting that followed the guidelines appeared to have a similar rate of activity (active in $68.8 \%$ of 32 nest-years) to those that had not been harvested $(G=0.692, P=0.405)$, but those that were harvested without application of the guidelines did not (active in $51.7 \%$ of 58 nest-years) $(G=11.644, P=0.001)$. When YrsUsed was controlled (LR), the difference between nesting areas cut with or without the guidelines and those without harvesting was similar to that noted above ( $P=0.183$ and $P=0.024$ for comparison of uncut areas to those harvested with and without the guidelines, respectively). Our sample size permitted us to detect a difference in rate of activity between cut and uncut nesting areas as small as $25 \%$ and $21 \%$ for areas cut with and without the guidelines, respectively.

When YrsUsed was controlled (LR), the activity status of nesting areas was not significantly related to the area or proximity of standard selection cuts (AreaStdSelection, DistStdSelection), light selection cuts (AreaLtSelection, DistLtSelection), light cuts (AreaLtCut, DistLtCut), or all cuts combined (AreaTotalCut, DistNearestCut) (Table 2). In contrast, activity status was negatively affected by the area and proximity of heavy cuts (AreaHeavyCut, DistHeavyCut). Activity status was also positively influenced by the area of uncut mature hardwood forest (AreaUncutHdwd) and the combined area of uncut and lightly selectioncut hardwood forest (AreaDenseHdwd) (Table 2).

When all variables were considered together (stepwise LR), YrsUsed $(P<0.001)$, DistHeavyCut $(P=0.020)$, and AreaD- 


\begin{tabular}{|c|c|}
\hline Variable & Description \\
\hline Activity status of nesting areas & $\begin{array}{l}\text { - considered active if a nest contained an incubating bird or was thickly decorated with conifer foliage or } \\
\text { covered with down feathers and had one or more birds observed nearby in April and early May }\end{array}$ \\
\hline Nest success & $\begin{array}{l}\text { - considered successful if there was evidence that well-developed chicks were present in late June - early } \\
\text { July }\end{array}$ \\
\hline YrsUsed & - number years nesting area known to have been used previously \\
\hline YrsSinceCut & - number nesting seasons since nesting area was harvested \\
\hline AreaLtSelection & $\begin{array}{l}\text { - area designated as modified under the guidelines and harvested using single tree selection system, resid- } \\
\text { ual basal area (BA) }>20 \mathrm{~m}^{2} / \mathrm{ha} \text {, residual canopy closure } \geq 70 \%\end{array}$ \\
\hline AreaStdSelection & $\begin{array}{l}\text { - area harvested using standard application of single tree selection system with a target residual BA of } \\
18-20 \mathrm{~m}^{2} / \text { ha, residual canopy closure } 60-70 \%\end{array}$ \\
\hline AreaLtCut & - AreaLtSelection + AreaStdSelection \\
\hline AreaHeavyCut & $\begin{array}{l}\text { - area harvested using single tree selection system with a target residual BA of } 14-16 \mathrm{~m}^{2} / \mathrm{ha} \text {, residual } \\
\text { canopy closure } 50-60 \% \text {; also includes uniform shelterwood seeding cuts with a residual BA of } 10- \\
14 \mathrm{~m}^{2} / \text { ha, residual canopy closure } 40-50 \%\end{array}$ \\
\hline AreaTotalCut & - total area harvested using any silvicultural system \\
\hline AreaUncutHdwd & - area uncut mature $(\geq 18 \mathrm{~m})$ tolerant or mid-tolerant hardwood forest \\
\hline AreaDenseHdwd & - AreaUncutHdwd + AreaLtSelection \\
\hline DistLtSelection & - minimum distance from primary nest to light selection harvest \\
\hline DistStdSelection & - minimum distance from primary nest to standard selection harvest \\
\hline DistLtCut & - minimum of DistLtSelection, DistStdSelection \\
\hline DistHeavyCut & - minimum distance from primary nest to heavy cut \\
\hline DistNearestCut & - minimum distance from primary nest to harvest, any type \\
\hline
\end{tabular}

enseHdwd $(P=0.025)$ were the best predictors of the activity status of nesting areas $\left(X^{2}=89.732, P<0.001, R^{2}=\right.$ $0.389)$. AreaHeavyCut $(P=0.250)$ did not enter the model, nor did the number of years since cutting had taken place (YrsSinceCut $)(P=0.781)$.

DistHeavyCut had a strong nonlinear effect on the activity status of nesting areas (Fig. 2). Heavy cuts right up to primary nests resulted in almost no re-use of nesting areas. Even when heavy cuts occurred $200 \mathrm{~m}$ from nests, the probability of nesting areas remaining active was less than half that in uncut forest.

To explore the relationship between DistHeavyCut and AreaDenseHdwd and their impact on the activity status of nesting areas, we developed a series of LR models to predict activity status based on YrsUsed and AreaDenseHdwd for different ranges of DistHeavyCut (from $<100$ to $500+\mathrm{m}$ in 100 $\mathrm{m}$ intervals). For each model, DistHeavyCut was incorporated as a dummy variable.

AreaDenseHdwd appeared to be able to compensate for DistHeavyCut, but only when heavy cuts were not too close to primary nests (Fig. 3). When DistHeavyCut was $<100 \mathrm{~m}$, there was a low probability of nesting areas being active (relative to those in uncut forest) regardless of AreaDenseHdwd (Fig. 3a). When DistHeavyCut was 100 to $199 \mathrm{~m}$, nesting areas had at most slightly more than half the probability of being active compared to those in uncut forest (Fig. 3b). When DistHeavyCut was 200 to $299 \mathrm{~m}$, nesting areas required close to 60 ha of uncut or lightly selection-cut hardwood forest to have a similar probability of being active to those in uncut forest (Fig. 3c). Beyond $300 \mathrm{~m}$, trends did not differ, so we pooled data. When DistHeavyCut was at least $300 \mathrm{~m}$, nesting areas with $\geq 20$ ha of uncut or lightly selection-cut hardwood forest within $500 \mathrm{~m}$ of the nest appeared to be active as frequently as those in uncut forest (Fig. 3d).

Nest Success: Nesting areas that had experienced harvesting had a similar success rate (successful in $62.2 \%$ of 37 nest-years) to those that had not (successful in $60.9 \%$ of 110 nest-years) ( $G=0.018, P=0.892$ ). Our sample size permitted us to detect a difference in success rate as small as $24 \%$.
Success rate also did not differ between nesting areas harvested with or without the guidelines (successful in 58.3\% of 12 nest-years and in $64.0 \%$ of 25 nest-years, respectively) and those with no harvesting $(G=0.030, P=0.863$ and $G=$ $0.083, P=0.774$, respectively). Our sample size permitted us to detect a difference in rate of success between cut and uncut nesting areas as small as 36\% and $26 \%$ for areas cut with and without the guidelines, respectively.

Nest success was not significantly influenced by YrsSinceCut $(P=0.486)$ or by any of the variables reflecting the area, type, or proximity of harvest (Table 2 ).

\section{Discussion}

As suggested by Bryant $(1986,1994)$, partial harvesting influenced the occupancy of nesting areas by red-shouldered hawks. This impact was not a consequence of direct disturbance by harvest activities as most cutting occurred outside the breeding season. Moreover, the impact clearly depended on the intensity of harvest. Shelterwood and heavy selection harvests had a negative effect on the activity status of the nesting area. In contrast, there was little evidence that lighter selection harvests had an effect.

Effects of harvesting likely occurred when changes in habitat structure reached specific suitability thresholds. Studies across the range of red-shouldered hawks suggest that canopy closure and/or basal area (BA) are key factors influencing habitat suitability. Suitable nesting habitat is characterized as having a mean canopy closure $>70 \%$ and mean total BA $>20 \mathrm{~m}^{2} / \mathrm{ha}$ (Titus and Mosher 1981, Armstrong and Euler 1982, Morris and Lemon 1983, Woodrey 1986, Preston et al. 1989, Szuba et al. 1991, Moorman and Chapman 1996, Dykstra et al. 2000, McLeod et al. 2000). Based on these criteria, our shelterwood and heavy selection harvests (40-60\% canopy closure, BA $10-16 \mathrm{~m}^{2} / \mathrm{ha}$ ) likely produced unsuitable habitat, standard selection harvests (60-70\% canopy closure, BA $\left.18-20 \mathrm{~m}^{2} / \mathrm{ha}\right)$ likely produced marginally suitable habitat, and light selection harvests $\left(\geq 70 \%\right.$ canopy closure, BA $>20 \mathrm{~m}^{2} / \mathrm{ha}$ ) likely maintained suitable habitat. 
Table 2. Effect of area, type, and proximity of harvesting on the probability that 1) nesting areas were active (activity status), and 2) active nests produced at least one fledgling (nest success) during a study of the effects of forest management practices on red-shouldered hawks in Ontario

\begin{tabular}{lcc}
\hline Variable $^{1}$ & Activity status & Nest success \\
\hline AreaLtSelection & $(+) 0.587^{2}$ & $(-) 0.951^{3}$ \\
AreaStdSelection & $(+) 0.818$ & $(-) 0.972$ \\
AreaLtCut & $(+) 0.750$ & $(-) 0.661$ \\
AreaHeavyCut & $(-) 0.038$ & $(-) 0.750$ \\
AreaTotalCut & $(-) 0.176$ & $(-) 0.768$ \\
AreaUncutHdwd & $(+) 0.003$ & $(-) 0.558$ \\
AreaDenseHdwd & $(+) 0.001$ & $(-) 0.637$ \\
DistLtSelection & $(-) 0.968$ & $(-) 0.344$ \\
DistStdSelection & $(+) 0.890$ & $(-) 0.733$ \\
DistLtCut & $(+) 0.712$ & $(-) 0.790$ \\
DistHeavyCut & $(+) 0.001$ & $(+) 0.347$ \\
DistNearestCut & $(+) 0.062$ & $(+) 0.989$ \\
\hline
\end{tabular}

${ }^{1}$ See Table 1 for definition of variables.

${ }^{2}$ Probability that coefficient of named variable was not significantly different from zero in logistic regression model including this variable and number of years nesting area was used previously (sign of regression coefficient in brackets).

${ }^{3}$ Probability that coefficient of named variable was not significantly different from zero in logistic regression model including only this variable (sign of regression coefficient in brackets).

Low residual BA and canopy closure may have made harvested forest less suitable for a number of reasons. Bryant (1986, $1994)$ suggested that low canopy closure $(<70 \%)$ may permit the larger and more aggressive, but less manoeuvrable, redtailed hawk (Buteo jamaicensis) to displace red-shouldered hawks. Low canopy closure might also have increased vulnerability to predation by great horned owls (Bubo virginianus), the most important predators of breeding red-shouldered hawks (Crocoll and Parker 1989, Bosakowski et al. 1992). Reduced canopy closure also encourages development of a dense understory of shrubs and saplings which might reduce the hunting efficiency of red-shouldered hawks in a manner similar to that suggested by Crocker-Bedford (1990) for northern goshawks (Accipiter gentilis).

While shelterwood and heavy selection harvesting reduced the re-use of nesting areas, proximity of harvest to primary nests had more influence than total area of harvests. Heavy cuts $>$ $300 \mathrm{~m}$ from nests appeared to have little effect on activity status as long as an adequate supply of dense mature hardwood nesting habitat remained. In our study area, red-shouldered hawks appeared to require at least 20 ha of mature uncut or lightly selection-cut hardwood forest within $500 \mathrm{~m}$ of primary nests. In other areas, red-shouldered hawks typically have $20-50$ ha of preferred forest habitat associated with nest sites (Sharp and Campbell 1982, Bosakowski et al. 1992, Bloom et al. 1993, Moorman and Chapman 1996, Howell and Chapman 1997).

Proximity and amount of harvesting did not affect nest success in this study. Similarly, Moorman and Chapman (1996) found no relationship between landscape features and success of red-shouldered hawk nests in Georgia. However, characteristics of habitat at finer scales may influence nest success. Dijak et al. (1990), Szuba et al. (1991), and Speiser and Bosakowski (1995) all found that success of red-shouldered hawk nests was related to either the presence or abundance of large trees in the vicinity of nest sites.

The number of nesting seasons since cutting occurred did not affect the activity status of nesting areas or nest success. However, we had few data on nests $>5$ nesting seasons after

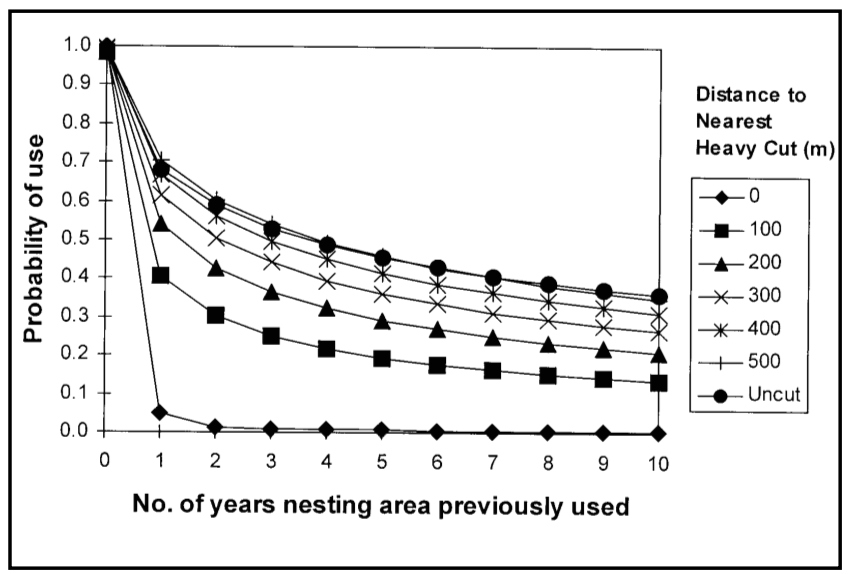

Fig. 2. Influence of distance to the nearest heavy cut (shelterwood seeding cut or selection cut with residual BA $14-16 \mathrm{~m}^{2} / \mathrm{ha}$ ) and number of years a nesting area was used previously on the probability of use of nesting areas by red-shouldered hawks.

harvest. We suspect that observed differences in activity status between nesting areas in selection-cut and uncut forest diminish as harvested forests grow and canopy closure and BA begin to exceed $70 \%$ and $20 \mathrm{~m}^{2} / \mathrm{ha}$, respectively.

\section{Management Implications}

Selection and shelterwood silvicultural systems are applied in the management of tolerant and mid-tolerant hardwood forest in Ontario to produce high-quality timber products (OMNR 1998). Our results suggest that application of these systems can also maintain suitable nesting habitat for red-shouldered hawks. Potential impacts can be mitigated by prohibiting shelterwood and heavy selection harvesting within $300 \mathrm{~m}$ of primary nests and by maintaining at least 20 ha of mature uncut or lightly selection-cut hardwood forest within $500 \mathrm{~m}$ of nests.

The current guidelines appeared to be effective; nesting areas harvested with the guidelines were re-used as frequently and produced young as frequently as those in uncut forest. When the reserve and modified area were arranged as concentric circles, the guidelines ensured that heavy cuts were at least $300 \mathrm{~m}$ from primary nests. However, when the modified area was offset to one side of the reserve, heavy cuts could have occurred within $300 \mathrm{~m}$. The guidelines should be modified to ensure no heavy cutting within $300 \mathrm{~m}$ of primary nests.

The guidelines require a $150-\mathrm{m}$ radius reserve $(7$ ha of mature uncut forest) and 21 ha of lightly selection-cut (or uncut) hardwood forest around primary nests. This total amount of dense mature forest ( $28 \mathrm{ha}$ ) is close to that suggested by our model ( $\geq 20 \mathrm{ha})$.

Our data do not indicate that amount of uncut forest or that distance to selection harvests with a BA $\geq 18 \mathrm{~m}^{2} / \mathrm{ha}$ had any effect on the activity status of nesting areas or nest success. Thus, the current 150-m reserve may be larger than necessary. However, some uncut forest likely should be retained around nests since other studies suggest that canopy closure or BA is higher at nests than in forest surrounding ( $>60 \mathrm{~m}$ from) nests (Morris and Lemon 1983, Woodrey 1986, Dykstra et al. 2000, McLeod et al. 2000) and nest success has been related to 

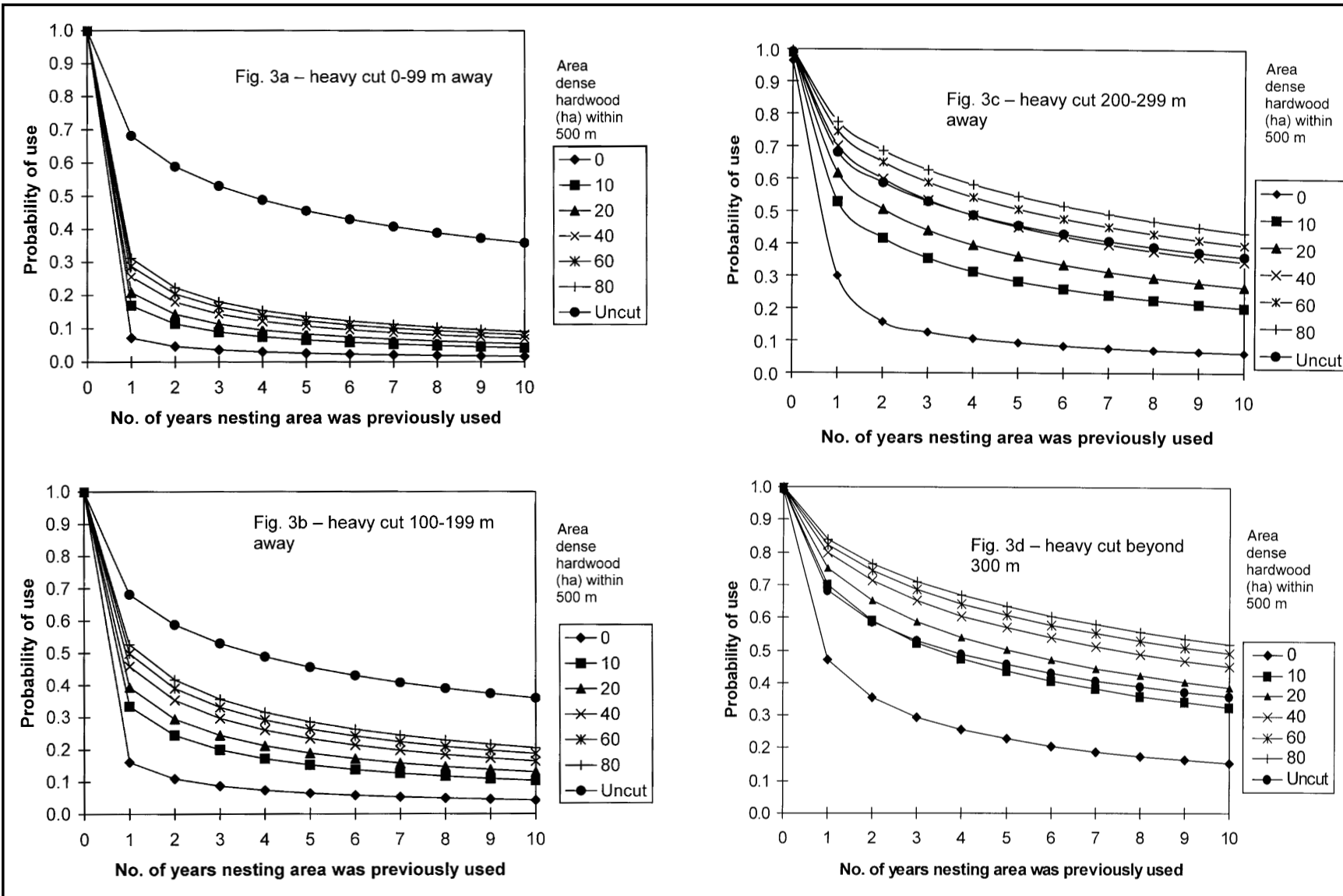

Fig. 3. Influence of the area of mature uncut and lightly selection-cut hardwood forest (AreaDenseHdwd) and the number of years a nesting area was used previously on the probability of use of nesting areas by red-shouldered hawks. Figs. a-d show relationships for heavy cuts (shelterwood seeding cuts and selection cuts with residual BA $14-16 \mathrm{~m}^{2} / \mathrm{ha}$ ) within 0 to $99 \mathrm{~m}, 100$ to $199 \mathrm{~m}, 200$ to $299 \mathrm{~m}$, or $300+\mathrm{m}$ of primary nests, respectively.

both canopy closure and BA (Szuba et al. 1991, Speiser and Bosakowski 1995).

Our results suggest some ways Ontario's red-shouldered hawk guidelines can be modified. However, this study was not a manipulative experiment and data were pseudo-replicated. Moreover, we were not able to evaluate the effects of harvesting during the nesting season. These limitations need to be considered when using results of this study to develop or revise forest management guidelines for this species.

\section{Acknowledgements}

This study was one of the first adaptive ecosystem management projects attempted in central Ontario by the OMNR. Its success was attributable to the integrated and dedicated efforts of biologists, foresters, wildlife technicians, forest technicians, tree markers, forest operators, consultants, and naturalists. It is a great pleasure to thank the many individuals who spent countless hours searching for and monitoring nests. Special thanks go to Karen Bellamy, Ron Black, Eric Boysen, Mike Buss, Kerry Coleman, Vince Ewing, Dave Ferguson, Tim Haxton, Bruce Hood, Jan McDonnell, Howard Mulholland, Mark Stabb, Martin Streit, Merilyn Twiss, and Mike Wilton. These individuals not only looked for and monitored nests, but were instrumental in setting up this project and supporting it through thick and thin.
We thank Chris McDonell, Tim Haxton, Martin Streit, Ian Thompson, and two anonymous reviewers for comments on various drafts of this manuscript. We are also indebted to Forestry Canada for its financial support of this project through the Northern Forestry Program of the Northern Development Agreement.

\section{References}

Armstrong, E. and D. Euler. 1982. Habitat usage of two woodland Buteo species in central Ontario. Can. Field-Nat. 97: 200-207.

Bloom, P.H., M.D. McCrary and M.J. Gibson. 1993. Red-shouldered hawk home-range and habitat use in southern California. J. Wildl. Manage. 57: 258-265.

Bosakowski, T., D.G. Smith and R. Speiser. 1992. Status, nesting density, and macrohabitat selection of red-shouldered hawks in northern New Jersey. Wilson Bull. 103: 434-446.

Bryant, A.A. 1986. Influence of selective logging on red-shouldered hawks, Buteo lineatus, in Waterloo Region, Ontario, 1953-1978. Can. Field-Nat. 100: 520-525.

Bryant, A.A. 1994. Habitat change and species replacement: the case of red-shouldered and red-tailed hawks. In M.K. McNicholl and J.L. Cranmer-Byng (eds.). Ornithology in Ontario. pp. 229-235. Hawk Owl Publishing, Whitby, Ontario.

Chambers, B.A., B.J. Naylor, J. Nieppola, B. Merchant and P. Uhlig. 1997. Field guide to forest ecosystems of central Ontario. Ontario Ministry of Natural Resources, SCSS Field Guide FG-01. 
Crocker-Bedford, D.C. 1990. Goshawk reproduction and forest management. Wildl. Soc. Bull. 18: 262-269.

Crocoll, S.T. 1994. Red-shouldered hawk (Buteo lineatus). In A. Poole and F. Gill (eds.). The birds of North America. No. 107: 1-20.

Crocoll, S.T. and J.W. Parker. 1989. The breeding biology of broad-winged and red-shouldered hawks in western New York. J. Raptor Res. 23: 125-139.

Dijak, W.D., B. Tannenbaum and M.A. Parker. 1990. Nest-site characteristics affecting success and reuse of red-shouldered hawk nests. Wilson Bull. 102: 480-486.

Dykstra, C.R., J.L. Hays, F.B. Daniel and M.M. Simon. 2000. Nest site selection and productivity of suburban red-shouldered hawks in southern Ohio. Condor 102: 401-408.

Howell, D.L. and B.R. Chapman. 1997. Home range and habitat use of red-shouldered hawks in Georgia. Wilson Bull. 109: 131-144.

McLeod, M.A., B.A. Belleman, D.E. Andersen and G.W. Oehlert. 2000. Red-shouldered hawk nest site selection in north-central Minnesota. Wilson Bull. 112: 203-213.

Moorman, C.E. and B.R. Chapman. 1996. Nest-site selection of redshouldered and red-tailed hawks in a managed forest. Wilson Bull. 108: 357-368.

Morris, M.M.J. and R.E. Lemon. 1983. Characteristics of vegetation and topography near red-shouldered hawk nests in southwestern Quebec. J. Wildl. Manage. 47: 138-145.

Naylor, B. and K. Szuba. 1998. Locating red-shouldered hawk nests. In W.B. Ranta (ed.). Selected wildlife and habitat features: inventory manual for use in forest management planning. pp. 139-163. Queen's Printer for Ontario, Toronto, Ontario.

Naylor, B., S. Christilaw, A. Todd and C. Corbett. 1994. Red-shouldered hawk habitat supply analysis for Bruton and Clyde Townships, Algonquin Park, 1990-2000. Ontario Ministry of Natural Resources, CRST Tech. Rpt. No. 34.

NCSS 2000. PASS User's guide. NCSS, Kaysville, Utah.
OMNR 1998. A silvicultural guide for the tolerant hardwood forest in Ontario. Ontario Ministry of Natural Resources, Queen's Printer for Ontario, Toronto, Ontario.

Preston, C.R., C.S. Harger and H.E. Harger. 1989. Habitat use and nest-site selection by red-shouldered hawks in Arkansas. Southwestern Nat. 34: 72-78.

Richardson, C.T. and C.K. Miller. 1997. Recommendations for protecting raptors from human disturbance: a review. Wildl. Soc. Bull 25: 634-638.

Rowe, J.S. 1972. Forest Regions of Canada. Can. For. Ser. Publ. No. 1300.

Sharp, M.J. and C.A. Campbell. 1982. Breeding ecology and status of red-shouldered hawks (Buteo l. lineatus) in Waterloo Region. Ont. Field Biol. 36: 1-10.

Speiser, R. and T. Bosakowski. 1995. Relationships between habitat selection and productivity of red-shouldered hawks in New Jersey and New York. J. Raptor Res. 29: 66-67.

SPSS Inc. 1997. SPSS 9.0 user's guide. SPSS, Chicago, Illinois.

Szuba, K. and B. Naylor. 1998. Forest raptors and their nests in central Ontario. Ontario Ministry of Natural Resources, SCSS Field Guide FG-03.

Szuba, K.J., B.J. Naylor and J.A. Baker. 1991. Nesting habitat of red-shouldered hawks in the Great Lakes - St. Lawrence forest region of central and southeastern Ontario. Ontario Ministry of Natural Resources, COFTDU Tech. Rpt. No. 14.

Titus, K. and J.A. Mosher. 1981. Nest-site habitat selected by woodland hawks in the central Appalachians. Auk 98: 270-281.

West, P.W. 1995. Application of regression analysis to inventory data with measurements on successive occasions. For. Ecol. Manage. 71: 227-234.

Woodrey, M.S. 1986. Characteristics of red-shouldered hawk nests in southeast Ohio. Wilson Bull. 98: 466-469. 